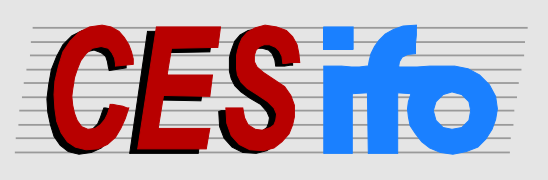

\title{
Working
}

Papers

www.cesifo.org/wp

\section{Improving Global Public Goods Supply through Conditional Transfers - The International Adaptation Transfer Riddle}

\author{
Karen Pittel \\ Dirk Rübbelke
}
CESIFO WORKING PAPER NO. 4106
CATEGORY 10: ENERGY AND CLIMATE ECONOMICS
FEBRUARY 2013
An electronic version of the paper may be downloaded
- from the SSRN website: Www.SSRN.com
- from the RePEc website: $\quad$ www.RePEc.org
- from the CESifo website: www.CESifo-group.org/wp

\section{CESifo}




\title{
Improving Global Public Goods Supply through Conditional Transfers - The International Adaptation Transfer Riddle
}

\begin{abstract}
In order to overcome the underprovision of global public goods various different policy approaches have been proposed. In the climate policy arena, international transfers are frequently seen as an effective means to raise the provision of the global public good 'climate change mitigation'. This paper focuses on a specific type of international transfer that aims at raising mitigation while also reducing the damages from climate change: conditional adaptation support. Especially since the COP in Copenhagen 2009, preparations are on-going to significantly expand international transfers that help developing countries to adapt to climate change. While there are extensive discussions in the policy arena about the required amount of adaptation funding and the best ways to raise, manage and disburse these funds, hardly any attention is paid to the international allocative effects of these transfers. The answer to the question of 'why' international adaptation transfers are paid at all, is often relegated to fairness considerations only. As adaptation benefits are largely local and adaptation transfers reduce the recipients' incentives to contribute to climate change mitigation, one would, however, expect at least unease in donor countries about plans to significantly expand international adaptation support. In this study, we compare two alternative conditional transfer schemes: one plainly subsidizes mitigation efforts, while the other provides adaptation support which is conditional on other agents' mitigation contributions. Disregarding distributional and fairness aspects the paper evaluates and compares the allocative effects of either policy scheme. It is shown that while both policy schemes can be beneficial for developing as well as industrialized countries, this outcome relies strongly on the productivity of mitigation and adaptation technologies.
\end{abstract}

JEL-Code: H410, H870, Q540.

Keywords: voluntary public good provision, conditional transfers, international climate policy, adaptation, mitigation.

\author{
Karen Pittel \\ Ifo Institute - Leibniz Institute for \\ Economic Research at the \\ University of Munich \\ Poschingerstraße 5 \\ Germany-81679 Munich \\ pittel@ifo.de
}

\author{
Dirk Rübbelke \\ Basque Centre for Climate Change (BC3) \\ Alameda Urquijo 4 \\ Spain - 48011 Bilbao \\ dirk.ruebbelke@bc3research.org
}




\section{Introduction}

Among the largest obstacles to the efficient provision of global public goods is the lack of an international coercive authority that can enforce an efficient provision level. So, global public goods like climate change mitigation rely solely on voluntarily contributions of individual countries. A logical prerequisite for a country to contribute voluntarily in such a setting would be the expectation to be at least not worse off after the contribution. One could consider this prerequisite as a kind of minimum requirement for participation in international climate policy. If a country voluntarily participated in a policy scheme that would leave it worse off, we would be facing a riddle.

International support for adaptation in other countries seems a promising candidate for such a riddle. Climate change adaptation creates mostly local benefits and hardly any international spill-overs that mitigation efforts of other countries would induce. So why should a country choose to delegate funds to international adaptation support? In this paper, we take a look at this potential riddle and investigate whether introducing adaptation support conditionality might not only solve the riddle but might even make adaptation support more attractive from the donor's point of view than direct mitigation support.

Efforts to internationally coordinate climate change policies have been largely delegated to conferences, so-called Conferences of Parties (COPs), under the United Nations Framework on Climate Change. In recent climate negotiations, international support of developing countries in adapting to climate change has become a strongly discussed issue. ${ }^{1}$ An important point of controversy is the share of international climate-related funding that should be dedicated to adaptation support. The Cancun Accords, agreed internationally at the COP in Cancun in 2010, stipulate that adaptation "must be addressed with the same priority as mitigation" (UNFCCC 2011). Thus, it is conceivable to expect that a large share of the 100 billion USD, having been pledged by industrialized countries in Cancun as an annual climaterelated transfer towards the developing world by 2020 , will be dedicated to adaptation tasks.

It seems a bit surprising - and there might be unease in industrialized countries - that such a large amount of money will be transferred internationally for adaptation projects in the developing world although the donor countries hardly benefit directly from these projects. Benefits of adaptation projects are largely local and thus, "[i]n contrast to mitigation, the benefits of adaptation are excludable" (Barrett 2008: 254) from an individual country's point

\footnotetext{
${ }^{1}$ Before, as Paavola and Adger (2006: 595) remark, there has been a "longstanding unease in the policy community with regard to adaptation" and this "originates from fears that the acknowledgement of a possibility of adaptation could distract international efforts to mitigate climate change."
} 
of view. ${ }^{2}$ Therefore, Tol (2005: 577) points out: “[n]ational governments and international organization have little to do with adaptation, and should not try."

Beyond, there are also strategic reasons for the unease with regard to adaptation support on the international level, because such support tends to reduce transfer-receiving countries' incentives to contribute to the global public good 'mitigation'. This is because adaptation reduces the vulnerability of these countries and hence also tends to decline their mitigation benefits. Put differently, to some extent mitigation and adaptation tend to be substitutes. As the merits of the global public good 'mitigation' are globally non-excludable, a decline in developing countries' contributions to this global public good - in turn - harms industrialized countries. ${ }^{3}$ Thus instead of awarding adaptation assistance, it seems more beneficial for donor countries to provide international support of mitigation only.

In order to find out whether there are nevertheless good reasons from an allocation perspective to provide international adaptation support, we compare the effects of different transfer schemes and consider whether these schemes can induce a Pareto improvement. Only when both parties - donors and recipients - benefit, they will pay or accept transfers.

As e.g. Buchholz and Konrad (1995) and Cornes and Hartley (2007) demonstrated, even unconditional international transfers can under specific conditions induce a Pareto improvement. Yet, because unconditional transfers only generate income effects, they are associated with dispersion losses as transfer receptors do not employ the whole transfer for climate change mitigation but use a portion for raising private good consumption (this share of private good consumption can be up to one, see e.g. Ono (1998) who considers the possibility of corner solutions). The augmentation of developing countries' private good consumption itself does however not improve the welfare of donor countries.

In contrast, transfers provided conditional on a rise in developing countries' mitigation efforts are more effective in increasing the level of the global public good 'mitigation' because they induce - additional to income effects - price effects. Consequently, they are more desirable from donor countries' point of view. The transfer-induced increase in global public good contribution by the developing world yields - via its positive global externalities - a return on the donor countries' investments in international transfers. "Due to its public-good character,

\footnotetext{
${ }^{2}$ Kane and Shogren (2000: 86) stress: "Adaptation is a private good in which the benefits of reduced severity" [of climate change effects] "accrue only to the nation."

3 An augmentation of "adaptation capabilities in one country will under standard conditions induce the other country to reduce its emissions and will imply a welfare loss in that country" (Ebert and Welsch 2012: 50).
} 
mitigation is the only channel through which the industrialised country can profit in this respect - contrary to the private good of adaptation" (Heuson et al. 2012: 5). ${ }^{4}$

In our model, which is based on an approach developed by Ihori (1996), conditional transfers are analyzed. We distinguish between conditional transfers provided in monetary terms (subsidies) and in-kind transfers. These in-kind transfers take the shape of support in adaptation to climate change. We investigate both induced changes in mitigation levels in developing countries as well as the conditions under which in-kind 'adaptation' transfers are more beneficial from both industrialized and developing countries' point of view than purely monetary mitigation subsidies. If we can determine conditions under which international adaptation support is more advantageous from all involved agents' perspective, then the current strong focus on adaptation transfers in the international climate policy arena might be justified. ${ }^{5}$ In order to investigate these aspects and to conduct a comparative statics analysis of potential influence factors, we transform standard welfare maximization problems into expenditure minimization problems (see e.g. Diamond and McFadden 1974 and Cornes 1992 for this dual approach). In our study, similar to the earlier analysis in a two-agent framework by Ebert and Welsch (2012), technological productivities play an important role. Yet, in contrast to Ebert and Welsch (2012), our study focuses on the influence of technological productivities on the effects of international transfers.

In detail we proceed as follows. Section 2 gives a short outline of the framework of this analysis. In the following Section 3, we concentrate on welfare maximization of the developing region within three scenarios. The first scenario describes the reference case where no transfers are provided and which is in line with the standard Nash scenario. Thereafter, we regard the two scenarios where international mitigation subsidies are provided and where mitigation efforts in developing countries are matched by international adaptation transfers. We depict the influence of the respective policies on the optimization problem of the developing region and ascertain the modification of effective mitigation prices. In Section 4, we reformulate the welfare maximization problems of the developing and industrialized regions as expenditure minimization problems in order to analyze the regional welfare effects

\footnotetext{
${ }^{4}$ As Buob and Stephan (2011a) state, the industrialized world can only benefit from investing in adaptation funding if it induces the developing world to raise its mitigation efforts, "which is the case if there is strict complementarity between mitigation and adaptation". In contrast to Buob and Stephan (2011a), in our setting adaptation funding can induce a rise in developing countries' mitigation although adaptation and mitigation are substitutes.

${ }^{5}$ Although no explicit conditionality of adaptation transfers is proclaimed in recent international agreements there might be such a conditionality pending. Still, the rules for the future annual USD100bn-transfers are not stipulated and the rules might be aligned with the developing countries' willingness to contribute to mitigation.
} 
of introducing subsidies and matching transfers. In order to do so, we distinguish in a comparative static analysis between different cases and scenarios. Section 5 concludes.

\section{The Model}

Consider a world consisting of a developing region $D$, and an industrialized region $I$. Both regions derive utility from the consumption of a private good bundle, $y_{i}, i=I, D$, and a global public good 'world-wide mitigation efforts', $X=\sum_{i} x_{i}$, with $x_{i}$ denoting the mitigation effort of region $i$. The benefits that a region derives from both, the private good bundle and the public good, depend on the level of adaptation $a_{i}$ to climate change.

Firstly, adaptation increases the benefits obtained from private good expenses. Total private consumption $c_{i}=c_{i}\left(y_{i}, a_{i}\right)$ is the effective private consumption derived from expenses in the private good bundle $y_{i}$ and the more adaptation takes place, the better this bundle (and its use) is protected against climate change, i.e. the higher is $c_{i}$ (with $c_{i y_{i}}>0$ and $c_{i a_{i}}>0$ ). For the intuition behind this assumption consider the following example: the benefits from owning a car will be higher if roads are not continuously flooded, i.e. the adaptation measure 'building a dike' raises the benefits from private goods.

Secondly, the effectively consumable amount of mitigation benefits in region $i$ depends on adaptation, $X_{i}^{c}=X_{i}^{c}\left(X, a_{i}\right)$ where $X_{i}^{c}$ is the adaptation adjusted benefit from global mitigation $X$. Similarly to Auerswald, Konrad and Thum (2011: 4) who assume adaptation to be a substitute measure for self-insurance against the risk from climate change, we suppose that higher regional adaptation reduces the benefits from mitigation in this region $\left(X_{i}^{c} a_{i}<0\right)$. Also Ingham, Ma and Ulph (2007: 5358) consider adaptation and mitigation to be substitutes, as "they are two different ways of reducing climate change damages, and if, say, the costs of adaptation fell, we expect society to do more adaptation and less mitigation." And Ingham, Ma and Ulph (2005a,b) show that adaptation and mitigation are in general substitutes, but they also identify cases where complementarity may prevail. For example, complementarity could arise when adaptation costs depend on the amount of mitigation conducted. ${ }^{6}$ Buob and Stephan (2011b) investigate both the case where marginal costs of adaptation inversely depend on global mitigation and the case where marginal costs of adaptation are independent of global mitigation.

\footnotetext{
${ }^{6}$ Also maladaptation may bring about complementarity of mitigation and adaptation (Ingham, Ma and Ulph 2005a: 14).
} 
Please note that while we assume that adaptation in region $i$ exerts a negative effect on the mitigation benefits in the same region, it seems reasonable to assume that the mitigation benefits in region $j$ are unaffected by region $i$ 's adaptation efforts $(i \neq j)$. Hence, as the adverse mitigation productivity effect of adaptation transfers is only perceived locally, it can be interpreted as a private effect (from the respective region's point of view).

Keeping the above defined relationships in mind, a region's welfare function is given by $U_{i}=U_{i}\left(c_{i}\left(y_{i}, a_{i}\right), X_{i}^{c}\left(X, a_{i}\right)\right)$, i.e. the utility depends on the effectively consumable outputs or characteristics $c_{i}$ and $X_{i}^{c}$ of the goods $y_{i}$ and $X=x_{i}+x_{j}$, respectively. Thus, in line with Lancaster (1966: 133), we break away from the 'traditional' approach 'that goods are the direct objects of utility" and suppose that it is instead the characteristics or outputs of the goods from which utility is derived; also see Gorman (1980) and Cornes and Sandler (1984) for such distinctions between goods and characteristics. Throughout we assume that the characteristics behave like normal 'goods'.

In this general set-up, each region allocates its exogenously given income $I_{i}$ on private goods and mitigation efforts. Prices of either good are set equal to unity.

In the following sections of the paper, we will assume that the industrialized region provides conditional adaptation or monetary transfers towards the developing world. As our focus is on the welfare effects of international transfers channelled towards the developing region, we abstract from industrialized region's investment in domestic adaptation (i.e. $a_{I}=0$ ). Regarding the developing region, we assume that $a_{D}$ is completely initiated by transfers from the industrialized region. One may argue that - due to better technological knowledge in industrialized countries - adaptation is more effective and cheaper when it is provided via transfers by industrialized countries and thus developing countries refrain from own 'less effective' domestic adaptation efforts.

Put it differently, we focus on the situation in which

- industrialized countries can commit within the framework of an international agreement to channel conditional transfers towards the developing world,

- the developing region is too poor and/or inexperienced to invest in adaptation itself,

- the industrialized region can choose between two policies: subsidizing mitigation and financing adaptation in the developing region. 


\section{Welfare Maximization in Different Support Schemes}

In this section we distinguish between three scenarios, 1) no international transfer policy, 2) mitigation activities in the developing region are subsidized by the industrialized world, and 3 ) the industrialized region grants adaptation support for the developing region conditional on its level of mitigation activity. By determining the conditions for the developing region's welfare maximization and ascertaining the resulting effective mitigation prices, we can show that each of these scenarios brings about different mitigation levels in the developing world. Based on these findings, we analyse welfare implications of the different international transfer schemes and varying technological productivities in Section 4 of this paper.

\subsection{No-policy scenario}

If no transfer policy is conducted by the industrialized region, region $D$ maximizes its welfare function (1) subject to its budget constraint $(2 a):^{7}$

$$
\begin{gathered}
\max _{y_{D}, x_{D}} U_{D}\left(c_{D}\left(y_{D}, a_{D}\right), X_{D}^{c}\left(X, a_{D}\right)\right) \\
\text { s.t. } I_{D}=y_{D}+x_{D} .
\end{gathered}
$$

As adaptation is not financed by the industrialized region in this scenario, $a_{D}=0$ holds and we assume for simplicity $c_{D}=y_{D}$ and $X_{D}^{c}=X$ in this case. The first-order conditions for the optimization problem in (1) and (2a) give rise to the well-known equalization of the marginal rate of substitution between the two goods to their price ratio:

$$
\frac{\frac{\partial U_{D}}{\partial X_{D}^{c}}}{\frac{\partial U_{D}}{\partial c_{D}}}=1
$$

with $\frac{\partial c_{D}}{\partial y_{D}}=\frac{\partial X_{D}^{c}}{\partial x_{D}}=1$. Policies that cause a decline in the right-hand side (RHS) and/or an increase in the left-hand side (LHS) of (3) would induce a higher level of region $D$ 's voluntary contributions to the global public good.

\subsection{Subsidies: Supporting Mitigation through Monetary Transfers}

If the industrialized region subsidizes mitigation efforts in the developing region, ${ }^{8}$ the modified budget constraint of the developing region reads

\footnotetext{
${ }^{7}$ Please note that the corresponding maximization problem of the industrialized region would look slightly different as there is no adaptation in the industrialized region. Thus, its welfare function can simply be stated as $U_{I}\left(y_{I}, X\right)$. The budget constraint is $I_{I}=y_{I}+x_{I}+T\left(x_{D}\right)$, where $T$ are the funds transferred towards the developing region depending on the level $x_{D}$ of its mitigation efforts.
} 


$$
I_{D}=y_{D}+(1-s) x_{D}, \quad 0<\mathrm{s}<1
$$

where $s$ is the subsidy rate paid by the industrialized region for climate change mitigation efforts in the developing region. As adaptation is not financed by the industrialized region in this policy scenario, $a_{D}=0$ and thus $c_{D}=y_{D}$ and $X_{D}^{c}=X$ still hold. Maximization of (1) subject to $(2 b)$ yields

$$
\frac{\frac{\partial U_{D}}{\partial X_{D}^{c}}}{\frac{\partial U_{D}}{\partial c_{D}}}=1-s .
$$

Compared with the no-policy scenario, the price ratio between private and public goods is lower and thus the mitigation level is higher in the subsidy case. The RHS of (4) can be interpreted as the effective price $p_{D}^{e, s}$ of public good provision and obviously this effective price has declined due to the international subsidy payments.

\subsection{Matching: Adaptation Support}

Instead of directly subsidizing mitigation, the industrialized region can finance in-kind transfers to the developing region with these transfers taking the form of adaptation measures. Transfers are conditional on the contribution of the developing region to mitigation, i.e. if the developing region provides $x_{D}$ units of mitigation, the industrialized region matches this provision by adaptation financing of $t \cdot x_{D}$. In the subsequent parts of this paper, we denote the policy scheme that matches mitigation with adaptation support shortly as 'matching scheme', ${ }^{9}$ while we denote the scheme that matches mitigation with monetary transfers (subsidies) as 'subsidy scheme'. ${ }^{10}$ We assume throughout that $s=t$, i.e. transfer payments per unit of $x_{D}$ are the same under subsidy and matching.

We interpret adaptation as a protection of private consumption against climate change such that the expenses $y_{D}$ translate in a higher consumable private good level

$$
\mathrm{c}_{\mathrm{D}}=\mathrm{y}_{\mathrm{D}}+\delta \mathrm{tx}_{\mathrm{D}}
$$

than in a situation without adaptation.

\footnotetext{
${ }^{8}$ Conditional transfers in international climate policy are provided, for example, via the Global Environmental Facility which collects funds from developed countries and channels these towards developing countries.

${ }^{9}$ In contrast to most applications or extensions of the standard matching model which was first developed by Guttman (1978), we do not consider mutual but one-sided matching. Unlike conventional matching models either considering the subsidization of public good purchases (e.g. Danziger and Schnytzer 1991, Althammer and Buchholz 1993) or the conditional contribution to the public good (e.g. Guttman 1987), we consider the conditional contribution to another agent's private good 'adaptation'.

10 Buchholz, Cornes and Rübbelke (2011, F4) point to the equivalence of matching schemes based on conditional public good supply and specific schemes based on subsidy payments.
} 
The monetary input $t x_{D}$ to the transfer scheme purchases adaptation $a_{D}$ which in turn produces the output of additional units of private characteristic consumption. We assume a linear relationship between the input and the output where $\delta>0$ measures the productivity of adaptation transfers in generating additional private characteristic consumption. We assume that the unit price of adaptation $a_{D}$ provided via international transfers - like the unit prices of all other goods - is equal to unity, such that we can write $a_{D}=t x_{D}$.

Furthermore, we assume that adaptation diminishes the effectively consumable amount $X_{D}^{c}$ of mitigation in the developing region as follows

$$
X_{D}^{c}=X_{D}^{c}\left(X, a_{D}\right)=X-\gamma t x_{D}
$$

where $\gamma>0$ is a constant parameter reflecting the mitigation-productivity diminishing effect of adaptation investments. Hence, the input $t x_{D}$ to the adaptation transfer scheme brings about a decline in the effectively consumable mitigation output by $\gamma t x_{D}$.

In the case of matching, maximization of welfare is again subject to the income constraint (2a), as in-kind adaptation transfers work through the change in effectively consumable outputs and thus through the arguments of the welfare function (1) only. Consequently, while subsidization in the previous subsection led to a modification of the developing region's budget constraint, financing adaptation affects the welfare function directly through its arguments $X_{D}^{c}$ and $c_{D}$.

Nevertheless, the effects of adaptation can - in a similar way as the effects in the subsidy scenario - be interpreted as effective price changes. However, in contrast to the subsidy scenario, we have to distinguish between the effective prices of goods and of characteristics. In the subsidy case, amounts of goods and characteristics were supposed to coincide, i.e. $c_{D}=y_{D}$ and $X_{D}^{c}=X$, and consequently also the effective prices of goods and characteristics were the same.

However, in the matching case, amounts of goods and characteristics differ. While the effective price per unit of the public good $x_{D}$ expressed in quantities of the private good $y_{D}$ abandoned remains unchanged, the effective price of consumable units of $x_{D}^{c}$ is modified. As we now consider effective prices in the characteristics dimension, the effective price $p_{D}^{e, m}$ of purchasing a unit $x_{D}^{c}$ has to reflect the amount of $c_{D}$ that has to be abandoned in exchange. From the first-order conditions obtained from the maximization of (1) subject to (2a), (5) and (6), we derive 


$$
\frac{\frac{\partial U_{D}}{\partial X_{D}^{c}}}{\frac{\partial U_{D}}{\partial c_{D}}}=\frac{1-t \delta}{1-t \gamma} .
$$

The RHS of (7) displays the effective price (in terms of $c_{D}$ that has to be abandoned in exchange) of purchasing one unit of $x_{D}^{c}$, i.e. $p_{D}^{e, m}=\frac{1-t \delta}{1-t \gamma}$ in the matching case. As we face multiple constraints we have to deal with a so-called 'points rationing' problem (Cornes and Sandler 1996: 259).

In a way similar to that of the subsidy payment (see (4)), the in-kind-transfer induced rise in private consumption reduces the numerator of the term on the RHS of (7). In contrast to the subsidy, however, the adaptation transfer also reduces the denominator of the RHS of (7). Summarized, we observe two opposing effects of adaptation transfers: On the one hand, adaptation transfers 'subsidize' public good provision by generating additional effective private characteristic consumption and thus make investments in public good provision more attractive. On the other hand, adaptation transfers reduce the productivity of public goods in generating domestic public benefits which in turn raises the attractiveness of private good purchases relative to public good contributions. In the following, we assume throughout that $\gamma<\delta$ such that the subsidization effect outweighs the effect on effectively consumable mitigation and the overall impact of adaptation transfers on the effective price is negative. Only when the effective price declines, a positive price effect on the developing region's demand for public good provision will arise. ${ }^{11}$

\section{Comparison between Subsidies and Matching}

In the following, the effects of subsidy and matching schemes on the welfare of the two regions are compared. For this comparison, we also have to consider the impact that the different policies have on the external benefits that arise from the provision of the global public good. To accomplish this, we consider the full income, $E_{i}$, of either region and not only its monetary income. A region's full income contains its monetary income plus the monetary value of the externalities received from the other region's public good provision

$$
E_{i}=I_{i}+p_{i}^{e, k} x_{j}=I_{i}+p_{i}^{e, k}\left(X-x_{i}\right)=y_{i}+p_{i}^{e, k} X,
$$

with $i, j=D, I, i \neq j$ and $k=m, s$ (for the use of the term 'full income' in the public good context also see Cornes and Sandler 1994: 409; in the rationing context Neary and Roberts

\footnotetext{
${ }^{11}$ To ensure for effective prices to be positive we impose the further parameter restriction $t \delta<1$.
} 
1980 and Rothbarth 1940-41 employ virtual magnitudes and Cornes and Sandler 1996: 262 use the term 'virtual income'). ${ }^{12}$

For the further analysis it proves to be convenient to translate the welfare maximization problem in (1) and (2a) into an expenditure minimization problem with a region minimizing the cost of attaining a given welfare level $\bar{U}_{i}$ at given prices.

For the developing region, this gives

$$
\min _{y_{D}, x_{D}} E_{D}=y_{D}+p_{D}^{e, k} X \quad \text { subject to } U_{D}=\bar{U}_{D}
$$

From the first-order conditions of (9), the developing region's compensated demand $X_{D}(\equiv$ $\left.\frac{\partial E_{D}}{\partial p_{D}^{e, k}}\right)$ for the public good

$$
X_{D}\left(\bar{U}_{D}, p_{D}^{e, k}\right)
$$

can be derived (see Cornes 1992: 70 and Ihori 1996: 142). Furthermore, we can express the optimal expenditure of region $D$ as a function of the effective price and the region's welfare level, $E_{D}\left(\bar{U}_{D}, p_{D}^{e, k}\right)$.

Analogously, we can proceed with respect to the industrialized region whose full income is given by (8) for $i=I$ and $p_{I}^{e, k}=1$ throughout as there are no transfers channelled towards the industrialized world. Expenditure minimization then gives the compensated demand for $X$ of the industrialized region

$$
X_{I}\left(\bar{U}_{I}, p_{I}^{e, k}\right)=X_{I}\left(\bar{U}_{I}, 1\right)
$$

and its optimal expenditure $E_{I}\left(\bar{U}_{I}, 1\right)$ for a given welfare level and given prices.

Multiplying the industrialized region's expenditure function by $p_{D}^{e, k}$, the developing region's expenditure function by $p_{I}^{e, k}=1$ and summing up the resulting functions gives

$$
E_{D}\left(\bar{U}_{D}, p_{D}^{e, k}\right)+p_{D}^{e, k} E_{I}\left(\bar{U}_{I}, 1\right)=p_{D}^{e, k} I_{I}+I_{D}+p_{D}^{e, k} X,
$$

where

$$
X=X_{D}\left(\bar{U}_{D}, p_{D}^{e, k}\right)=X_{I}\left(\bar{U}_{I}, 1\right)
$$

\footnotetext{
${ }^{12}$ Put differently, the full income indicates the hypothetical income required for purchasing the amount of all consumed characteristics, i.e. including the amount of public characteristics provided by the other region. In the matching case, for example, it holds for the full income of region $D$ that $E_{D}=c_{D}+p_{D}^{e, m}\left(x_{D}^{c}+x_{I}\right)=y_{D}+$ $x_{D} t \delta+p_{D}^{e, m}\left[x_{D}(1-t \gamma)+x_{I}\right]=I_{D}-\left(1-p_{D}^{e, m}(1-t \gamma)-t \delta\right) x_{D}+p_{D}^{e, m} x_{I}=I_{D}+\frac{1-t \delta}{1-t \gamma}\left(X-x_{D}\right) \quad$ when we take into account that the effective price of the public characteristic is the one displayed on the RHS of (7).
} 
holds with respect to global public good provision. From (11) and (12) we see that the interconnectedness of the two regions via the equilibrium condition for the global public good, (11), reduces the region's degree of freedom by one dimension. Consider, for example,

the effects of a policy induced change in the effective price, $p_{D}^{e, k}$. If the two regions could independently decide upon their demand for the two goods, each region's expenditure minimization problem (i.e. (9) for the developing region) would independently give the optimal change in the respective consumption bundles for given welfare levels $\bar{U}_{i}$. In a world, in which each region is affected by the other region's preference for the global public good, however, a new equilibrium allocation can only be attained if the welfare levels in the two regions are allowed to adjust as well. It is these policy induced welfare effects on which the focus of the following sections will be.

We assume that in the initial situation, no support of mitigation in the developing region is provided, i.e. in both regions the effective price of generating additional units of the public good is equal to unity.

\subsection{Subsidy Scheme}

We know from (4) that - in the subsidy scenario - the effective price of generating additional units of the public good in the developing region is

$$
p_{D}^{e, s}=1-s
$$

which implies

$$
\frac{d p_{D}^{e, s}}{d s}=-1
$$

A marginal increase in the subsidy rate affects the industrialized region's monetary income as follows:

$$
d I_{I}=-x_{D} d s
$$

To analyse the effects of subsidization on the two regions, we derive from (11):

$$
\begin{aligned}
\frac{\partial E_{D}}{\partial U_{D}} d U_{D}+p_{D}^{e, s} \frac{\partial E_{I}}{\partial U_{I}} d U_{I} & =-E_{I} \frac{d p_{D}^{e, s}}{d s} d s+I_{I} \frac{d p_{D}^{e, s}}{d s} d s+p_{D}^{e s} d I_{I}+p_{D}^{e, s} \frac{\partial X_{I}}{\partial U_{I}} d U_{I} \\
& =E_{I} d s-I_{I} d s+p_{D}^{e, s} d I_{I}+p_{D}^{e, s} \frac{\partial X_{I}}{\partial U_{I}} d U_{I}
\end{aligned}
$$

where we have replaced $\bar{U}_{i}$ by $U_{i}$ to indicate that welfare levels adjust endogenously to subsidy induced price changes.

Furthermore, it follows from (12) that 


$$
\frac{\partial X_{I}}{\partial U_{I}} d U_{I}-\frac{\partial X_{D}}{\partial U_{D}} d U_{D}=-\frac{\partial X_{D}}{\partial p_{D}^{e s}} d s
$$

Gathering (15), (16) and (17), we get

$$
\left[\begin{array}{cc}
p_{D}^{e, s} \frac{\partial c_{I}}{\partial U_{I}} & \frac{\partial E_{D}}{\partial U_{D}} \\
\frac{\partial X_{I}}{\partial U_{I}} & -\frac{\partial X_{D}}{\partial U_{D}}
\end{array}\right]\left[\begin{array}{l}
d U_{I} \\
d U_{D}
\end{array}\right]=\left[\begin{array}{c}
\left(E_{I}-I_{I}\right)-p_{D}^{e, s} x_{D} \\
-\frac{\partial X_{D}}{\partial p_{D}^{e, s}}
\end{array}\right] d s
$$

where $\frac{\partial E_{i}}{\partial U_{i}} \equiv p_{i}^{e, s} \frac{\partial X_{i}}{\partial U_{i}}+\frac{\partial c_{i}}{\partial U_{i}}, \frac{\partial X_{i}}{\partial U_{i}}>0$ and where $c_{i}\left(U_{i}, p_{i}^{e, s}\right)$ is the compensated demand function for private consumption in region $i(i=D, I)$ with $\frac{\partial c_{i}}{\partial U_{i}}>0$.

From (18), we can now derive the welfare effects of introducing a mitigation subsidy. For the industrialized region, we obtain:

$$
\begin{aligned}
\frac{d U_{I}}{d s} & =\frac{\left[\left(I_{I}-E_{I}\right)+p_{D}^{e, s} x_{D}\right] \frac{\partial X_{D}}{\partial U_{D}}+\frac{\partial X_{D} \partial E_{D}}{\partial p_{D}^{e, s} \partial U_{D}}}{\Delta_{S}}=\frac{\left[x_{D}\left(p_{D}^{e, S}-1\right)\right] \frac{\partial X_{D}}{\partial U_{D}}+\frac{\partial X_{D} \partial E_{D}}{\partial p_{D}^{e, S} \partial U_{D}}}{\Delta_{S}} \\
& =\frac{p_{D}^{e, s} x_{D} \frac{\partial X_{D}}{\partial U_{D}}}{\Delta_{S}}-\frac{x_{D} \frac{\partial X_{D}}{\partial U_{D}}-\frac{\partial E_{D} \partial X_{D}}{\partial U_{D} \partial p_{D}^{e, s}}}{\Delta_{S}}>0
\end{aligned}
$$

where $\Delta_{S}=-p_{D}^{e, S} \frac{\partial c_{I}}{\partial U_{I}} \frac{\partial X_{D}}{\partial U_{D}}-\frac{\partial E_{D}}{\partial U_{D}} \frac{\partial X_{I}}{\partial U_{I}}<0$. In the initial situation where no support of mitigation in the developing region is provided it holds that $\Delta_{S}=-\left(\frac{\partial c_{I}}{\partial U_{I}} \frac{\partial X_{D}}{\partial U_{D}}+\frac{\partial E_{D}}{\partial U_{D}} \frac{\partial X_{I}}{\partial U_{I}}\right)$ which we label for later use $\Delta^{0}$. The first term in the second row of (19) is the effect of the decline in income $I_{I}$ which is due to the payment of the subsidy. The second term reflects the effect of a decrease in the effective price of public good provision $p_{D}^{e, s}$ faced by the developing region and it includes an income and a substitution price effect.

The total income effect arising from the introduction of the subsidy is given by:

$$
T I E_{s u b}^{I}=\left[p_{D}^{e, s}-1\right] \frac{x_{D} \frac{\partial X_{D}}{\partial U_{D}}}{\Delta_{s}} .
$$

As initial prices, $p_{i}^{e *}$, before introduction of a subsidy were assumed to be equal to unity in both regions, the individual income effects $\frac{p_{D}^{e, s} x_{D} \frac{\partial X_{D}}{\partial U_{D}}}{\Delta^{0}}$ and $-\frac{x_{D} \frac{\partial X_{D}}{\partial U_{D}}}{\Delta^{0}}$ perfectly offset each other. The substitution price effect is:

$$
S P E_{\text {sub }}^{I}=\frac{\frac{\partial X_{D} \partial E_{D}}{\partial p_{D}^{e, S} \partial U_{D}}}{\Delta_{s}}>0
$$

Consequently, the subsidy payment and associated decrease in the effective price of mitigation for the developing country raise the industrialized region's welfare. 
For the developing region, the welfare effect of a subsidy introduction is given by (see (18)):

$$
\begin{gathered}
\frac{d U_{D}}{d s}=\frac{\left[\left(I_{I}-E_{I}\right)+p_{D}^{e, S} x_{D}\right] \frac{\partial X_{I}}{\partial U_{I}}-p_{D}^{e, s} \frac{\partial c_{I} \partial X_{D}}{\partial U_{I} \partial p_{D}^{e, s}}}{\Delta_{S}}=\frac{\left[x_{D}\left(p_{D}^{e, S}-1\right)\right] \frac{\partial X_{I}}{\partial U_{I}}-p_{D}^{e, S} \frac{\partial c_{I} \partial X_{D}}{\partial U_{I} \partial p_{D}^{e, S}}}{\Delta_{S}} \\
=\frac{p_{D}^{e, S} x_{D} \frac{\partial X_{I}}{\partial U_{I}}}{\Delta_{S}}-\frac{x_{D} \frac{\partial X_{I}}{\partial U_{I}}+p_{D}^{e, s} \frac{\partial c_{I} \partial X_{D}}{\partial U_{I} \partial p_{D}^{e, s}}}{\Delta_{S}}<0 .
\end{gathered}
$$

The first term in the second row of (22) shows the effect which the transfer-induced decline of monetary income in the industrialized region has on welfare in the developing region. Predictably, this effect is negative as the reduction in income reduces the industrialized regions contribution to mitigation. As before in the discussion of the industrialized region, the second term reflects the effect of a decrease in the effective price of public good provision $p_{D}^{e, s}$ faced by the developing region. Also again, it encompasses an income and a substitution price effect.

The total income effect for the developing region is given by:

$$
T I E_{s u b}^{D}=\left[p_{D}^{e, s}-1\right] \frac{x_{D} \frac{\partial X_{I}}{\partial U_{I}}}{\Delta_{s}}
$$

where, again, the two income effects perfectly offset each other. The corresponding substitution price effect is equal to

$$
S P E_{\text {sub }}^{D}=-\frac{p_{D}^{e, s} \frac{\partial c_{I}}{\partial U_{I}} \frac{\partial X_{D}}{\partial p_{D}, S}}{\Delta_{s}}<0,
$$

and hence - as it is negative -, the transfer-receiving developing region loses welfare.

The surprising result that the transfer-paying industrialized region gains welfare while the receiving developing region loses welfare can be explained as follows. The conditional monetary transfer raises the developing region's demand for and supply of the public good. The rise in the developing region's public-good supply - in turn - is like a transfer in-kind to the industrialized world and as we assumed that both private and public characteristic consumption behave like normal goods, "increasing such a transfer induces a higher demand for private consumption and thus a lower contribution to the public good" (for this explanation and quote see Buchholz and Peters 2005: 29) in the industrialized region. 


\subsection{Matching Scheme: Reference Scenario with $\delta=1$}

When considering the effects of matching transfers on welfare it proves to be helpful to first consider the special case in which the productivity of adaptation in generating additional units of the consumable private good $c_{D}$ is equal to unity, i.e. $\delta=1$. Thus, the monetary input to the adaptation transfer scheme $\left(t x_{D}=a_{D}\right)$ is equal to its output, i.e. the monetary value of additional private characteristic consumption $\left(t x_{D} \delta=t x_{D}\right)$. In the course of Section 4.2 we focus on this simplified case in our interpretation of the general results. The case of $\delta>1$ is dealt with subsequently in Section 4.3.

\subsubsection{Effects of Matching Transfers on the Industrialized Region's Welfare}

To analyze the influence of matching transfers on the welfare of the transfer paying industrialized region, we proceed in a stepwise fashion: In step one, we regard a simplified case in which adaptation has no 'productivity effect' on mitigation, i.e. $\gamma=0$ and therefore $X_{D}^{c}=X$ ('Case 1'). Step two then comprises the analysis of the complete, i.e. the 'real' case where all adaptation effects are taken into account, i.e. $\gamma \neq 0$ and $X_{D}^{c}=X-\gamma t x_{D}$ ('Case 2'). This stepwise procedure allows us to get a better intuition on the differential effects of matching transfers versus subsidy payments.

Case 1: In this first matching case, the developing world faces the effective price $p_{D}^{e, m^{\prime}}=1-$ $t \delta$ of public characteristic generation. The corresponding expenditure function is given by

$$
E_{D}=I_{D}+(1-t \delta) x_{I}
$$

It holds that

$$
\frac{\partial E_{D}}{\partial U_{D}} d U_{D}+p_{D}^{e, m^{\prime}} \frac{\partial E_{I}}{\partial U_{I}} d U_{I}=E_{I} \delta d t-I_{I} \delta d t+p_{D}^{e, m^{\prime}} d I_{I}+p_{D}^{e, m^{\prime}} \frac{\partial X_{I}}{\partial U_{I}} d U_{I}
$$

A marginal change in the transfer rate affects the industrialized region's monetary income in the same way as the change in the subsidy rate in the previous subsection (see (15)):

$$
d I_{I}=-x_{D} d t
$$

In equivalence to (18), welfare changes due to the introduction of a matching scheme can now be derived from (17), (26a) and (27): 


$$
\left[\begin{array}{cc}
p_{D}^{e, m^{\prime}} \frac{\partial c_{I}}{\partial U_{I}} & \frac{\partial E_{D}}{\partial U_{D}} \\
\frac{\partial X_{I}}{\partial U_{I}} & -\frac{\partial X_{D}}{\partial U_{D}}
\end{array}\right]\left[\begin{array}{l}
d U_{I} \\
d U_{D}
\end{array}\right]=\left[\begin{array}{c}
\delta\left(E_{I}-I_{I}\right)-p_{D}^{e, m^{\prime}} x_{D} \\
-\delta \frac{\partial X_{D}}{\partial p_{D}^{e, m}}
\end{array}\right] d t
$$

We get for the industrialized region:

$$
\frac{d U_{I}}{d t}=\frac{\left[x_{D}\left(p_{D}^{e, m^{\prime}}-\delta\right)\right] \frac{\partial X_{D}}{\partial U_{D}}+\delta \frac{\partial E_{D} \partial X_{D}}{\partial U_{D} \partial p_{D}^{e, m}}}{\Delta_{1}}=\frac{p_{D}^{e, m^{\prime}} x_{D} \frac{\partial X_{D}}{\partial U_{D}}}{\Delta_{1}}-\frac{\delta\left[x_{D} \frac{\partial X_{D}}{\partial U_{D}}-\frac{\partial E_{D} \partial X_{D}}{\partial U_{D} \partial p_{D}^{e, m}}\right]}{\Delta_{1}}>0
$$

where $\Delta_{1}=-p_{D}^{e, m^{\prime}} \frac{\partial c_{I}}{\partial U_{I}} \frac{\partial X_{D}}{\partial U_{D}}-\frac{\partial E_{D}}{\partial U_{D}} \frac{\partial X_{I}}{\partial U_{I}}<0$. In the initial situation where no support of mitigation in the developing region is provided $\Delta_{1}=\Delta^{0}$ holds.

The first term on the rightmost side of (29a) represents - comparable to (19) in the subsidy case - the effect of a decline in income $I_{I}$, now due to the expenditure for the in-kind transfer. Also as in (19), the second term reflects the effect of the decrease in the developing region's effective price of public good provision, now $p_{D}^{e, m^{\prime}}$, which again results in an income and a substitution price effect.

The total income effect in the industrialized region now equals

$$
T I E_{\text {match }}^{I, C 1}=\left[p_{D}^{e, m^{\prime}}-\delta\right] \frac{x_{D} \frac{\partial X_{D}}{\partial U_{D}}}{\Delta_{1}}
$$

If one unit of adaptation induces one additional unit of private consumption, i.e. $\delta=1$, we are again in a situation in which both income effects perfectly offset each other (recall that the initial effective price $p_{D}^{e, m^{\prime}}$ was assumed to be unity). In this case the matching transfer is unambiguously welfare enhancing for the industrialized region, as the substitution price effect is positive:

$$
S P E_{\text {match }}^{I, C 1}=\delta \frac{\frac{\partial X_{D}}{\partial p_{D}^{e, m} \cdot \frac{\partial E_{D}}{\partial U_{D}}}}{\Delta_{1}}>0
$$

As we can observe by comparing (20) and (30a) as well as (21) and (31a) respectively, subsidy and matching scheme exert the same income and substitution price effects as long as $\delta=1$ and the effects of adaptation on mitigation benefits are disregarded. In this case, both schemes are equivalent and raise the industrialized region's welfare level.

Case 2: For $\gamma \neq 0$, the effective price of providing an additional unit of the public characteristic, $p_{D}^{e, m}=\frac{1-t \delta}{1-t \gamma}$, is higher than the effective price in Case 1, i.e. $p_{D}^{e, m}>p_{D}^{e, m^{\prime}}$. The 
adverse mitigation productivity effect of adaptation implies a lower characteristic level $X_{D}^{c}$ obtained from the public good $X$ in the developing region. This lower productivity translates into a higher effective price for raising the consumption level of the public characteristic in the developing region. ${ }^{13}$ We now face a case similar to the one analysed by Ihori (1996: 146149) where different productivities in producing a public good prevail in subsidizing and subsidized regions.

The modified expenditure function of the developing region now reads

$$
E_{D}=I_{D}+\frac{1-t \delta}{1-t \gamma} x_{I}
$$

(26a) changes accordingly to

$$
\frac{\partial E_{D}}{\partial U_{D}} d U_{D}+p_{D}^{e, m} \frac{\partial E_{I}}{\partial U_{I}} d U_{I}=E_{I} \frac{\delta-\gamma}{(1-t \gamma)^{2}} d t-I_{I} \frac{\delta-\gamma}{(1-t \gamma)^{2}} d t+p_{D}^{e, m} d I_{I}+p_{D}^{e, m} \frac{\partial X_{I}}{\partial U_{I}} d U_{I}(26 \mathrm{~b})
$$

and gathering (17), (26b) and (27) gives

$$
\left[\begin{array}{cc}
p_{D}^{e, m} \frac{\partial c_{I}}{\partial U_{I}} & \frac{\partial E_{D}}{\partial U_{D}} \\
\frac{\partial X_{I}}{\partial U_{I}} & -\frac{\partial X_{D}}{\partial U_{D}}
\end{array}\right]\left[\begin{array}{l}
d U_{I} \\
d U_{D}
\end{array}\right]=\left[\begin{array}{c}
\left(E_{I}-I_{I}\right) \frac{\delta-\gamma}{(1-t \gamma)^{2}}-p_{D}^{e, m} x_{D} \\
-\frac{\partial X_{D}}{\partial p_{D}^{e, m}} \frac{\delta-\gamma}{(1-t \gamma)^{2}}
\end{array}\right] d t
$$

From (28b), we obtain

$$
\begin{aligned}
\frac{d U_{I}}{d t} & =\frac{\left[x_{D}\left(p_{D}^{e, m}-\frac{\delta-\gamma}{(1-t \gamma)^{2}}\right)\right] \frac{\partial X_{D}}{\partial U_{D}}+\frac{\delta-\gamma}{(1-t \gamma)^{2}} \frac{\partial E_{D}}{\partial U_{D}} \frac{\partial X_{D}}{\partial p_{D}^{e, m}}}{\Delta_{2}} \\
& =\frac{p_{D}^{e, m} x_{D} \frac{\partial X_{D}}{\partial U_{D}}}{\Delta_{2}}-\frac{\frac{\delta-\gamma}{(1-t \gamma)^{2}}\left[x_{D} \frac{\partial X_{D}}{\partial U_{D}}-\frac{\partial E_{D}}{\partial U_{D}} \frac{\partial X_{D}}{\left.\partial p_{D}^{e, m}\right]}\right.}{\Delta_{2}},
\end{aligned}
$$

where $\Delta_{2}=-p_{D}^{e, m} \frac{\partial c_{I}}{\partial U_{I}} \frac{\partial X_{D}}{\partial U_{D}}-\frac{\partial E_{D}}{\partial U_{D}} \frac{\partial X_{I}}{\partial U_{I}}<0$. Initially, when no support of mitigation in the developing region is provided, we again have $\Delta_{2}=\Delta^{0}$.

The interpretation of the different components of (29b) follows the same lines as the interpretation of (29a). Equivalently, the modified expressions for the total income and the substitution price effect now read

$$
T I E_{\text {match }}^{I, C 2}=\left[p_{D}^{e, m}-\frac{\delta-\gamma}{(1-t \gamma)^{2}}\right] \frac{x_{D} \frac{\partial X_{D}}{\partial U_{D}}}{\Delta_{2}},
$$

${ }^{13}$ Conversely, private ancillary benefits of climate protection are frequently modelled to offset the cost of respective protection activities and thus to reduce the effective price of climate protection (see, e.g., Ekins 1996: 163, Rübbelke 2002: 105). 


$$
S P E_{\text {match }}^{I, C 2}=\frac{\delta-\gamma}{(1-t \gamma)^{2}} \frac{\frac{\partial X_{D}}{\partial p_{D}^{e, m}} \frac{\partial E_{D}}{\partial U_{D}}}{\Delta_{2}}>0,
$$

where, even for $\delta=1$, the sign of the total income effect is ambiguous while the substitution price effect remains unambiguously positive. For $\delta=1$, the ambiguity of the income effect results directly from the effect that adaptation has on mitigation productivity and thus on the effective price. We come back to this effect in the discussion below.

\section{Discussion of Cases 1 and 2:}

In (29a) and (29b) substitution price effect and one income effect are positive, while the other income effect (first term on the RHS of (29a) and in the second row of (29b) respectively) is negative.

As we can easily observe from a comparison between (29a) and (29b), the implications of the negative mitigation-productivity effect of adaptation for the industrialized region's welfare are ambiguous as $\delta \lesseqgtr \frac{\delta-\gamma}{(1-t \gamma)^{2}}$, (recall that $\Delta_{1}=\Delta_{2}=\Delta^{0}$ initially). Compared to Case 1 , the adverse mitigation-productivity effect reduces welfare in the industrialized region only if

$$
\gamma>\frac{2 t \delta-1}{t^{2} \delta}, \quad \text { resp. } \quad \gamma>\frac{2 t-1}{t^{2}} \quad \text { for } \quad \delta=1 .
$$

If (32) holds for $\delta=1$, not only the total income effect is negative but even the total welfare effect can become negative (see (29b)). For this to happen, the positive substitution price effect has to be dominated by the now negative total income effect which is more likely if $\frac{\partial E_{D}}{\partial U_{D}} \frac{\partial X_{D}}{\partial p_{D}^{e, m}}$ is small while $x_{D} \frac{\partial X_{D}}{\partial \bar{U}_{D}}$ is large. ${ }^{14}$ If, however, (32) does not hold for $\delta=1$, the industrialized region's welfare gain is even higher than in Case 1. As Case 1 and the subsidy case are equivalent under the assumptions made, the subsidy scheme is preferred by the industrialized region if (32) holds while matching is preferred if (32) does not hold.

Inequality (32) tends to hold with large mitigation productivity losses induced by adaptation (which is reflected by a large $\gamma$ ). This is in accordance with intuition: the donor region strives for inducing a decline in the effective price of public good provision in the developing region. Yet, a high mitigation productivity loss has a strong effective-price raising effect in the developing region (see denominator on the RHS of (7)).

\footnotetext{
14 The total welfare effect becomes negative, if $(1+(t \gamma-2) t) \gamma x_{D} \frac{\partial X_{D}}{\partial U_{D}}>(\gamma-1) \frac{\partial E_{D}}{\partial U_{D}} \frac{\partial X_{D}}{\partial p_{D}^{e, m}}$. A necessary condition for this to happen is that $1+(t \gamma-2) t>0$ which is equivalent to condition (32).
} 
Also in accordance with intuition, (32) tends to hold for low values of $t$ and $\delta$, as this implies a low effective-price reducing influence of the transfer (see RHS of (7) and take into account that $\delta>\gamma) .{ }^{15}$ In this case, the price-reducing influence of a low transfer rate $t$ is incapable to countervail the adverse price effect of the mitigation productivity loss.

Summarizing the results for $\delta=1$, the industrialized region always gains in Case 1 - like in the equivalent subsidy setting - from its payment of transfers towards the developing region. The influence of the mitigation-productivity diminishing effect of adaptation on the welfare change induced by transfers is, however, ambiguous (Case 2). Surprisingly, adaptationinduced adverse effects on the productivity of mitigation in the developing region might even be beneficial from the transfer payer's point of view. As adaptation reduces the amount of public characteristics enjoyed in the developing region, this region might be induced to raise its public good contribution in order to counter this loss. It is more likely that this happens, when high rates $t$ and $\delta$ as well as a small adverse effect of adaptation on mitigation productivity (reflected by a small $\gamma$ ) prevail. Then, the industrialized region will prefer the use of the matching scheme and it will not provide monetary transfers.

\subsubsection{Effects of Matching Transfers on the Developing Region's Welfare}

Again, we assume in a first case that adaptation has no productivity effect on mitigation, i.e. $X_{D}^{c}=X$. Thereafter, in a second case, we consider the situation where $X_{D}^{c}=X-t x_{D} \gamma$.

Case 1: As in the discussion of Case 1 from the industrialized region's point of view, the effective price of the public good for the developing region is $p_{D}^{e, m^{\prime}}=1-t \delta$.

From (28a), we now derive the effect of the matching transfer on the developing region's welfare

$$
\begin{aligned}
\frac{d U_{D}}{d t} & =\frac{\left[x_{D}\left(p_{D}^{e, m^{\prime}}-\delta\right)\right] \frac{\partial X_{I}}{\partial U_{I}}-\delta p_{D}^{e, m^{\prime}} \frac{\partial c_{I}}{\partial U_{I}} \frac{\partial X_{D}}{\partial p_{D}^{e, m^{\prime}}}}{\Delta_{1}} \\
& =\frac{p_{D}^{e, m^{\prime}} x_{D} \frac{\partial X_{I}}{\partial U_{I}}}{\Delta_{1}}-\frac{\delta\left[x_{D} \frac{\partial X_{I}}{\partial U_{I}}+p_{D}^{e, m^{\prime}} \frac{\partial c_{I} \partial X_{D}}{\partial U_{I} \partial p_{D}^{e, m}}\right]}{\Delta_{1}} .
\end{aligned}
$$

Again, the welfare change results from two income effects and one substitution price effect. As the case for the subsidy scheme (and also for the industrialized region), one income effect

\footnotetext{
${ }^{15}$ Differentiation of the RHS of (32) with respect to $\delta$ resp. $t$ yields positive values (recall that $1-\delta t>0$ ).
} 
(first term in the second row of (33a)) is negative while the other (i.e. $-\delta x_{D} \frac{\partial X_{I}}{\partial U_{I}} / \Delta_{1}$ ) is positive. The total income effect in the industrialized region in the considered Case 1 is given by:

$$
T I E_{m a t c h}^{D, C 1}=\left[p_{D}^{e, m^{\prime}}-\delta\right] \frac{x_{D} \frac{\partial X_{I}}{\partial U_{I}}}{\Delta_{1}}
$$

Again, if $\delta=1$, and the initial effective price (before introduction of the matching scheme) is equal to unity, both income effects perfectly offset each other.

The substitution price effect

$$
S P E_{\text {match }}^{D, C 1}=-\delta \frac{p_{D}^{e, m^{\prime}} \frac{\partial c_{I} \partial X_{D}}{\partial U_{I \partial p_{D}^{e, m}}^{e, m}}}{\Delta_{1}}<0 .
$$

is negative for the developing region (in contrast to the respective effect in the industrialized region but in accordance with the results for the subsidy scheme).

Overall, the matching transfer unambiguously reduces the welfare in the developing region for $\delta=1$ due to the negative substitution price effect. Equivalent to the results for the industrialized region in Case 1, subsidy and matching scheme induce the same income and substitution price effects for $\delta=1$ (compare (23) to (34a) and (24) to (35a)). Thus, subsidy and matching schemes are again equivalent and, in case of the developing region, reduce welfare unambiguously.

Case 2: The effective price in this case is again $p_{D}^{e, m}=\frac{1-t \delta}{1-t \gamma}$. From $(29 \mathrm{~b})$, the overall effect of a change in the transfer rate is now equal to

$$
\begin{aligned}
\frac{d U_{D}}{d t} & =\frac{\left[x_{D}\left(p_{D}^{e, m}-\frac{\delta-\gamma}{(1-t \gamma)^{2}}\right)\right] \frac{\partial X_{I}-\frac{\delta-\gamma}{\partial U_{I}}}{(1-t \gamma)^{2}} p_{D}^{e, m} \frac{\partial c_{I}}{\partial U_{I}} \frac{\partial X_{D}}{\partial p_{D}^{e, m}}}{\Delta_{2}} \\
& =\frac{p_{D}^{e, m} x_{D} \frac{\partial X_{I}}{\partial U_{I}}}{\Delta_{2}}-\frac{\frac{\delta-\gamma}{(1-t \gamma)^{2}}\left[x_{D} \frac{\partial X_{I}}{\partial U_{I}}+p_{D}^{e, m} \frac{\partial c_{I}}{\partial U_{I} \partial x_{D}} \frac{\partial x_{D}}{\Delta_{2}}\right]}{\Delta_{2}}
\end{aligned}
$$

with the total income effect and the substitution price effect equalling:

$$
\begin{gathered}
\text { TIE } E_{\text {match }}^{D}=\left[p_{D}^{e, m}-\frac{\delta-\gamma}{(1-t \gamma)^{2}}\right] \frac{x_{D} \frac{\partial X_{I}}{\partial U_{I}}}{\Delta_{2}}, \\
S P E_{\text {match }}^{D}=-\frac{\delta-\gamma}{(1-t \gamma)^{2}} \frac{p_{D}^{e, m} \frac{\partial c_{I} \partial X_{D}}{\partial U_{I} \partial p_{D}^{e, m}}}{\Delta_{2}}<0 .
\end{gathered}
$$


The interpretation of $(33 b)-(35 b)$ is equivalent to the interpretation of $(29 b)-(31 b)$, i.e. Case 2 for the industrialized region. As in (30b), the sign of the total income effect is ambiguous while the substitution price effect is now negative. Whether or not the overall welfare effect is negative depends, as for the industrialized region, on the strength of the transfer induced effects on consumption and mitigation as well as on the transfer rate.

\section{Discussion of Cases 1 and 2:}

Like for the industrialized region, Case 1 and the subsidy case are equivalent from the developing world's point of view. Regarding Cases 1 and 2, we can easily see from a comparison of (34a) and (34b) as well as of (35a) and (35b) respectively, that the strength of the positive income effect as well as of the negative substitution price effect change due to the adverse effect of adaptation on the productivity of mitigation. Whether the developing region's welfare rises or falls due to this additional effect on mitigation depends on the relative size of the induced changes, specifically - as in the case of the industrialized region on $\delta \gtrless \frac{\delta-\gamma}{(1-t \gamma)^{2}}$. According to (33a) and (33b) welfare is reduced if
a) $\gamma>\frac{2 t \delta-1}{t^{2} \delta}, \quad$ and $x_{D} \frac{\partial X_{I}}{\partial U_{I}}>p_{D}^{e, k}\left|\frac{\partial c_{I}}{\partial U_{I}} \frac{\partial X_{D}}{\partial p_{D}^{e, k}}\right|$, or if
b) $\gamma<\frac{2 t \delta-1}{t^{2} \delta}, \quad$ and $x_{D} \frac{\partial X_{I}}{\partial U_{I}}<p_{D}^{e, k}\left|\frac{\partial c_{I}}{\partial U_{I}} \frac{\partial X_{D}}{\partial p_{D}^{e, k}}\right|$,

with $p_{D}^{e, m^{\prime}}=p_{D}^{e, m}(=1)$ in the ex-ante situation and consequently $k=m^{\prime}, m$. If a) or b) hold for $\delta=1$, the developing region would be better off under a subsidy scheme than under a matching scheme.

The strength of the negative substitution price effect relative to the positive income effect, or more specifically, the size of $p_{D}^{e, k}\left|\frac{\partial c_{I}}{\partial U_{I}} \frac{\partial X_{D}}{\partial p_{D}^{e, k}}\right|$ relative to $x_{D} \frac{\partial X_{I}}{\partial U_{I}}$ is crucial for the question of whether a) or b) applies. If the income effect is stronger than the substitution price effect, then $\gamma>\frac{2 t \delta-1}{t^{2} \delta}$ implies that welfare decreases in the developing region due to the effect of adaptation on mitigation productivity. Essentially, the comparative statics with respect to the model parameters are the same in this case as for the industrialized region before. A higher $\gamma$ and thus a lower decrease of the effective price of public good provision $p_{D}^{e, s}$ affect welfare negatively (see (33a) and (33b)) while a positive effect on welfare becomes more likely if the adverse effect of adaptation on mitigation is small (reflected by a small $\gamma$ ). A high transfer rate $t$ and a strong impact of adaptation on the benefits from private good consumption as 
reflected by a large $\delta$ (we discuss the latter case in more detail in Section 4.3) would also be beneficial in a).

Condition b) applies when the substitution price effect is stronger than the positive income effect, i.e. if $p_{D}^{e, k}\left|\frac{\partial c_{I}}{\partial U_{I}} \frac{\partial X_{D}}{\partial p_{D}^{e, k}}\right|$ is larger than $x_{D} \frac{\partial X_{I}}{\partial U_{I}}$. In this case the aggregate contribution of the negative substitution price effect and the positive income effect to total welfare in (33a), resp. (33b), is negative. Consequently, a transfer induced decrease in the effective price of the public good $\left(\frac{\partial p_{D}^{e, m^{\prime}}}{\partial t}=-\delta ; \frac{\partial p_{D}^{e, m}}{\partial t}=-\frac{\delta-\gamma}{(1-t \gamma)^{2}}\right)$ affects total welfare negatively. So, if the change in the effective price is higher when $\gamma$ is positive, the reduction in total welfare will be stronger in Case 2 than in Case 1. This is the case for $\gamma<\frac{2 t \delta-1}{t^{2} \delta}$. From a comparative statics perspective, the total adverse welfare effect now becomes stronger with lower levels of $\gamma$ and higher levels of $t$ and $\delta$. In turn, a low transfer rate, a small positive effect of abatement on private consumption and a strong negative effects of abatement on mitigation would make a welfare reduction due to the adverse effect of adaptation on mitigation less likely. Please note that b) cannot arise for the industrialized region as the substitution price effect is positive for region $I$, i.e. the sum of substitution price effect and positive income effect is always positive.

Summarized, surprisingly the decline in the productivity of mitigation in the developing region may have a positive welfare effect on this region. This resembles the results of Buchholz and Konrad (1994) who find in a multi-stage game that countries may have an incentive to choose an abatement technology which is more costly than others in the first stage of the game.

As we can observe from these findings and (32), the effects of matching on the welfare of the industrialized and developing regions depend crucially on $\delta \gtrless \frac{\delta-\gamma}{(1-t \gamma)^{2}} \Leftrightarrow \gamma \gtrless \frac{2 t \delta-1}{t^{2} \delta}$ and on the relative size of substitution price and positive income effect in the developing region. Depending on the parameterization of $t, \gamma$ and $\delta$ either region may win or lose. A matching scheme, however, may become beneficial for both regions only if $\delta<\frac{\delta-\gamma}{(1-t \gamma)^{2}}$ and the positive income effect dominates the substitution price effect. If, however, $\delta<\frac{\delta-\gamma}{(1-t \gamma)^{2}}$ and the positive income effect is dominated by the substitution price effect, then the developing region would prefer the subsidy scheme. 


\subsection{Comparison of Policy Schemes: Alternative Technological Productivities}

In the previous section we concentrated on the special case in which an adaptation transfer unit enhanced the effective consumption of the private good by exactly the same amount as the purchase of another unit of the private good would have done. In this section, we relax this very specific assumption and take a look at more general constellations in which we allow not only $\delta$ but also the effective ex-ante price $p_{D}^{e *}$, i.e. the effective price before the payment of international transfers, ${ }^{16}$ to differ from unity.

In the first scenario we assume that the productivity $\delta$ of in-kind adaptation transfers in generating additional private consumption is higher than in the reference scenario discussed in Section 4.2, i.e. $\delta>1$.

In a second scenario, we suppose that the effective price of the public good is ex ante, i.e. before a transfer is introduced, smaller than unity in the developing world.

Throughout the analysis of both scenarios we keep the assumption that $\delta>\gamma$, i.e. adaptation transfers cause effective costs of public good contributions to decline, and $t=s$, i.e. matching and subsidy rates are equal.

\section{Alternative Scenario 1: $\delta>1, p_{D}^{e *}=1$}

In this scenario $t=s<t \delta$ and consequently the productivity of adaptation transfers in raising private good benefits is higher than in the Reference Scenario where $\delta$ is equal to unity. As a result, the reduction of the effective price due to matching transfers is stronger for $\delta>1$ than for $\delta=1$.

In Alternative Scenario 1, as we can see from (30a), the total income effect on the industrialized region's welfare increases compared to Case 1 of the Reference Scenario, i.e. the case where the adaptation effect on mitigation productivity is ignored. The same holds true when the effect of adaptation on mitigation is not omitted (Case 2), as can be seen from (30b). Yet, while the income effect becomes unambiguously positive in (30a), the sign of the total income effect in (30b) remains ambiguous. It only becomes positive (and hence more beneficial than the one in the subsidization setting), when the positive income effect $\frac{\frac{\gamma-\delta}{(1-t \gamma)^{2}} x_{D} \frac{\partial X_{I}}{\partial U_{I}}}{\Delta}$ induced by the effective-price decline in the developing region exceeds the

\footnotetext{
${ }^{16}$ Akai (2003) discusses the different implications of cost-differentials in public good provision generated by public policies and those differentials already existing before policy implementation for income transfer policy.
} 
negative income effect $\frac{p_{D}^{e, m} x_{D} \frac{\partial X_{I}}{\partial U_{I}}}{\Delta}$ caused by the monetary income loss in the industrialized region, i.e. if $1-\frac{\delta-\gamma}{(1-t \gamma)^{2}}<0$ (compare (20) and 30b) and recall that $p_{D}^{e, m}=1$ in the pretransfer situation). As we know from (30a) and (30b), the total income effect can even become larger in Case 2 than in Case 1 (which is the case if $\delta<\frac{\delta-\gamma}{(1-t \gamma)^{2}}$ holds). Regarding the substitution price effects, these are larger in Case 1 as well as in Case 2 for $\delta>1$ than for $\delta=1$ (see (31a) and (31b)).

Summarized, a higher productivity of the employed abatement technology raises the utility that the industrialized region obtains from its adaptation transfers and might even cause matching contributions to become advantageous over subsidy payments. The latter holds throughout in Case 1 of the Alternative Scenario 1. Basically, for $\delta>1$ and $t=s$, adaptation transfers lower the developing region's opportunity costs of public good provision by more than a subsidy payment and as a result, the welfare of the industrialized region increases. This finding is in line with Cornes and Hartley (2007: 215) who show that a reduction in an agent's unit cost of public good provision raises all other agents' welfare. This result also resembles the finding by Ebert and Welsch (2012) in a different two-country setting, that conversely - improvements in the benefits from greenhouse gas emissions, and consequently an increase in the marginal cost of mitigation, ${ }^{17}$ have negative effects on the other country's welfare. In our model the benefits of mitigation activities $x_{D}$ in the developing region are raised (and with it the effective price of mitigation characteristics reduced) through the receipt of adaptation transfers and thus, conversely, welfare in the industrialized region improves.

In contrast, in Case 2 of the Alternative Scenario 1, matching contributions are not advantageous throughout, as the adaptation-induced loss in mitigation productivity (as reflected by $\gamma$ ) causes the effective price to rise compared to Case 1. From the industrialized world's point of view, the matching scheme in Case 2 is only more advantageous than the subsidy scheme, if the decrease in the effective price is higher under matching than under subsidization, i.e. if $\frac{\delta-\gamma}{(1-t \gamma)^{2}}>1$ (compare (19) and (29b)).

In the developing region - as in the industrialized region before - the total income effects are larger in both cases of the Alternative Scenario 1 than the ones in the respective cases of the

17 "The emission enhancing effect of productivity improvements is intuitive, since such improvements imply an increase in the benefits foregone when emissions are reduced, that is, an increase in marginal mitigation costs" (Ebert and Welsch 2012: 59). 
Reference Scenario. Again, the total income effect is always positive in Case 1, while it only becomes positive for $\frac{\delta-\gamma}{(1-t \gamma)^{2}}>1$ in Case 2 .

Also as in the industrialized region, the substitution price effects are stronger due to the stronger decrease in the effective price. Since the substitution price effect is negative for the developing region, this implies, however, a stronger drag on welfare while the stronger substitution price effect enhanced welfare in the industrialized region. Whether a higher productivity parameter $\delta$ improves or worsens welfare in the developing world, depends, as in the Reference Scenario, on the relative strength of substitution price and income effects.

The developing region's welfare in the matching setting (Case 2) exceeds the one in the subsidy setting - as we can observe from a comparison of (22) and (33b) - only if
a) $\frac{\delta-\gamma}{(1-t \gamma)^{2}}>1, \quad$ and $x_{D} \frac{\partial X_{I}}{\partial U_{I}}>p_{D}^{e, k}\left|\frac{\partial c_{I}}{\partial U_{I}} \frac{\partial X_{D}}{\partial p_{D}^{e, k}}\right|$, or if
b) $\frac{\delta-\gamma}{(1-t \gamma)^{2}}<1, \quad$ and $x_{D} \frac{\partial X_{I}}{\partial U_{I}}<p_{D}^{e, k}\left|\frac{\partial c_{I}}{\partial U_{I}} \frac{\partial X_{D}}{\partial p_{D}^{e, k}}\right|$,

with $p_{D}^{e, m}=p_{D}^{e, s}(=1)$ in the ex-ante situation and thus $k=m, s{ }^{18}$

Under the matching scheme, an increase in the productivity indicator $\delta$ consequently makes a positive welfare effect of the decline in the effective public-good price (second term in the second row of (33b)) more likely if $x_{D} \frac{\partial X_{I}}{\partial U_{I}}>p_{D}^{e, k}\left|\frac{\partial c_{I}}{\partial U_{I}} \frac{\partial X_{D}}{\partial p_{D}^{e, k}}\right|$, i.e. if the involved positive income effect exceeds the magnitude of the substitution price effect. If $\frac{\delta-\gamma}{(1-t \gamma)^{2}}>1$ in this case, the welfare effect of matching is less negative than the welfare effect of subsidization. Provided that $\frac{\delta-\gamma}{(1-t \gamma)^{2}}$ is sufficiently high, the welfare effect of matching might even become positive. Thus, efforts of the industrialized region to increase the effectiveness of adaptation support would in a) also have a positive effect on the developing region's welfare.

However, if $x_{D} \frac{\partial X_{I}}{\partial U_{I}}<p_{D}^{e, k}\left|\frac{\partial c_{I}}{\partial U_{I}} \frac{\partial X_{D}}{\partial p_{D}^{e, k}}\right|$, the total welfare effect of a decline in the effective public good price is negative, i.e. the involved positive income effect is smaller than the substitution price effect. In contrast to a), matching can never enhance welfare compared to the no-policy scenario in this case. At best, the policy-induced welfare loss will be lower than under subsidization. If $b$ ) holds, matching is only advantageous compared to subsidization from the developing region's point of view, if the transfer-induced decline in the effective public good

\footnotetext{
${ }^{18}$ In Case $1, \gamma=0$ and as $\delta>1$, only condition a) is relevant. So, if $x_{D} \frac{\partial X_{I}}{\partial U_{I}}<p_{D}^{e, k}\left|\frac{\partial c_{I}}{\partial U_{I}} \frac{\partial X_{D}}{\partial p_{D}^{e, k}}\right|$ holds in Case 1 , the developing region will always be worse of under matching than under subsidies.
} 
price is lower than in the subsidy scheme, i.e. if $\frac{\delta-\gamma}{(1-t \gamma)^{2}}<1$. As in this case a lower $\delta$ would be advantageous from the developing region's perspective, region $D$ might find it paradoxically in its best interest to prevent $\delta$ from being too high that is to prevent adaptation support from being too efficient.

Summarized, an improvement of the productivity (in raising private consumption) of adaptation support channelled towards the developing countries tends to raise the welfare in industrialized countries. Therefore, donor regions have a strong interest to disburse adaptation transfers in the way that most effectively raises the developing world's private consumption $c_{D}$. Actually, industrialized regions might even benefit more when adaptation support has an adverse effect on mitigation-productivity ( $\gamma$ is positive) in the developing world (see discussion concerning inequality (32)). The latter could be the case as the adverse effect of adaptation on mitigation-productivity might induce the developing region to compensate some of the public-characteristic loss by additional contributions to the good $x_{D}$. Due to the positive international spillovers of $x_{D}$ towards the donor region, the industrialized world would benefit from a higher level of the global public good provision $x_{D}$ by the developing region.

In contrast, developing regions may prefer a less effective adaptation 'technology' generating a lower level of additional private characteristic consumption. Thus, we may face a principalagent situation where the donor of transfers is the principal and the transfer receiving region is the agent and where there might be a risk that the agents have an incentive to waste or misguide adaptation resources. ${ }^{19}$

\section{Alternative Scenario 2: $\delta \geq 1, p_{D}^{e *}<1$}

Regularly, cheaper climate change mitigation options are supposed to exist in developing countries as the present application of very polluting technologies in these countries can be overcome at lower cost than improving the already rather clean technologies in industrialized countries. In that sense, mitigation projects in developing countries tend to be more productive than those in industrialized countries.

\footnotetext{
19 It should be noted that the productivity of adaptation support in generating additional private consumption might also affect the impact of adaptation on mitigation benefits that is $\frac{\partial X_{D}^{c}\left(X, a_{D}\right)}{\partial a_{D}}$. This might in turn strengthen or weaken potential incentives to waste adaptation resources (see (33b)).
} 
In our model, a productivity advantage of the developing region in global public good provision can be translated into an effective ex-ante price $p_{D}^{e *}$ smaller than 1 . For the industrialized region this implies higher total income effects from subsidies as well as matching transfers and thus higher policy-induced welfare gains, respectively lower policyinduced welfare losses (see (19), (29a) and (29b)). Thus, the transfer paying industrialized region unambiguously gains from supporting cheaper climate change mitigation in the developing region.

In the developing region, the higher mitigation productivity also has a positive influence on the total income effect under subsidization as well as matching (see (23), (34a), and (34b)). Simultaneously, the negative substitution price effect (see (24), (35a), and (35b)) is weakened by the lower ex-ante price $p_{D}^{e *}$. Despite the positive effects of higher mitigation productivity on income and substitution price effects in the transfer receiving region, it may, however, still lose welfare due to the industrialized region's subsidy or matching transfer payments. For the subsidy scheme, these results for the Alternative Scenario 2 are consistent with the earlier findings in Ihori (1996: 147-148).

While the above results confirm that a high mitigation productivity in developing countries can make both conditional monetary and in-kind transfers capable to bring about a Pareto improvement, this can, however, not be taken for granted as the discussion above has shown. For Case 2 of the matching scheme, transfers become welfare improving for both regions (see (29b) and (33b)), if the positive one of the two income effects in the developing country exceeds the negative substitution price effect and if the productivity of adaptation in generating additional units of the private characteristic is sufficiently high, that is if

$$
\delta>\gamma+(1-t \gamma)^{2} p_{D}^{e, m} x_{D} \cdot \max \left\{A_{D}, A_{I}\right\}
$$

with

$$
A_{D}=\frac{\partial X_{I}}{\partial U_{I}}\left(x_{D} \frac{\partial X_{I}}{\partial U_{I}}+p_{D}^{e, m} \frac{\partial c_{I}}{\partial U_{I}} \frac{\partial X_{D}}{\partial p_{D}^{e, m}}\right)^{-1} ; A_{I}=\frac{\partial X_{D}}{\partial U_{D}}\left(x_{D} \frac{\partial X_{D}}{\partial U_{D}}-\frac{\partial E_{D}}{\partial U_{D}} \frac{\partial X_{D}}{\partial p_{D}^{e, m}}\right)^{-1}
$$

Assuming that the second-order effects of a reduction of $p_{D}^{e, m}$ are not too strong, (36) is more likely to hold, the smaller $p_{D}^{e, m}$. So, a high productivity differential between the regions makes a mutual profitability of matching more likely. ${ }^{20}$

Despite our result that matching can be welfare enhancing for both regions when it is realistically assumed that productivity differentials in producing the public good exist, this

\footnotetext{
${ }^{20}$ Please note that matching can never be welfare enhancing for both regions if the positive income effect in the developing country is lower the negative substitution price effect. In this case $\gamma+(1-t \gamma)^{2} p_{D}^{e, m} A_{I}<\delta<\gamma+$ $(1-t \gamma)^{2} p_{D}^{e, m} A_{D}$ would have to hold. As $A_{D}<0$, this condition can, however, never be fulfilled.
} 
alone cannot explain why international climate policy focuses so much on adaptation finance, as these productivity differentials tend to affect the welfare of countries under both schemes (subsidy and matching) in the same direction. For the subsidy scheme and Case 1 of the matching scheme, conditions under which both regions gain can be derived equivalently to (36).

\section{Conclusions}

Industrialized countries pledged 100 billion USD as an annual climate-related transfer towards the developing world by 2020 . Our analysis investigated in which way such transfers channelled from industrialized to developing countries could lead to welfare improvements not only in the developing world but also in developed countries. As international spillover effects are the main payback channel for industrialized countries' investments in transfers, we focused on schemes involving conditional transfers that reduce the effective price of the provision of the global public good 'climate change mitigation' in developing countries. In one of these schemes (subsidy scheme), such mitigation efforts in the developing region were plainly subsidized via conditional monetary transfers. In an alternative scheme (matching scheme), mitigation efforts in the developing region were matched by conditional in-kind transfers dedicated to adaptation to climate change in developing countries.

By using an expenditure minimization approach we confirmed that conditional transfers may harm the transfer receiving region while they tend to improve the welfare of the donor region. This seemingly paradoxical result is already known from earlier studies (e.g. Bergstrom 1989, Ihori 1996). We, however, also showed that both regions can win (or lose) in the case of conditional adaptation transfers, a result which, to our knowledge, is new to the literature. Whether regions win or lose depends crucially on the feedback effect of adaptation on the benefits from mitigation in the developing region. Not surprisingly, we also found that reducing effective prices of climate change mitigation via conditional transfers (both matching and subsidies) will bring about a higher level of climate change mitigation in the transfer receiving region.

From the developing countries' perspective, whether or not adaptation support (matching) would be preferred to a subsidy scheme, depends not only on the productivity of adaptation but also on the relative strength of income and substitution price effects. In contrast to a subsidy scheme, matching can result in a welfare increase for developing countries even if they do not possess a comparative advantage with respect to their mitigation productivity. 
Yet, even if adaptation technologies were favorable in the sense that such a positive welfare effect could theoretically arise, setting the appropriate transfer rate would require knowledge about the strength of the substitution and income effects which is rather unrealistic.

From the donors' point of view, a direct comparison of subsidy and matching schemes shows that matching tends to be less attractive than subsidization if adaptation and mitigation are strong substitutes. This tends to hold regardless of the ex-ante productivity of mitigation as reflected by the effective pre-policy price of the public good. However, a low pre-policy price in the developing region makes the absolute profitability of matching (and subsidization) more likely. Without this absolute profitability, i.e. without beneficial or with adverse effects, agents would not choose matching although it is more attractive (less adverse) than subsidization.

The pending relative disadvantage of the matching scheme from the donor's point of view stems from the adverse effect of adaptation support on the productivity of mitigation in developing countries which tends to cause a decline in these countries' willingness to contribute to global public good provision. Therefore, even when adaptation support schemes may be beneficial for both considered regions, the subsidy scheme may remain superior from the donors' perspective. Consequently, from the donors' point of view, self-protection via domestic adaptation to climate change might be preferable to adaptation support in developing countries. This domestic "self-protection has strategic advantages as it transfers greater responsibility for international environmental problems to other countries" (Zehaie 2009: 349). Support of adaptation abroad, however, implies an export of such advantages to the transfer receiving countries.

We found, however, also that - depending on the calibration of the model - matching can become more attractive than subsidization from the industrialized region's point of view. We showed that this outcome becomes more likely with low adverse mitigation productivity effects of adaptation and high transfer rates. It is especially the adaptation technology's productivity that can make matching more attractive and may therefore - from an allocation point of view - justify the current high interest in the climate policy arena to provide adaptation support: The matching scheme might become the preferred scheme from both transfer donors' and recipients' point of view, when productivity of the adaptation technology provided by the industrialized region in raising private consumption is very high. Yet, this potential justification for international adaptation transfers still requires empirical evidence.

Furthermore, we have seen that situations may arise where developing countries might even have incentives to misguide or waste adaptation support. Decision makers should be aware of 
the risk that principal-agent situations may arise where the agents receiving transfers have an interest to misguide funds in order to gerrymander the prevailing scheme such that their domestic welfare is maximized. Incentives should be given that discourage transfer receiving regions from doing so.

Summing up, our above findings show that while an allocation-based justification of international adaptation transfers as substitutes for mitigation subsidies can be found, this holds only under very specific circumstances. Overall, the strong international support for adaptation transfer remains, at least from an allocative point of view, a riddle.

Matters become even more complex if one considers intertemporal aspects of adaptation support. As adaptation support might only be superior to a subsidy scheme in bringing about a welfare improvement for both involved regions if the adaptation productivity remains permanently high (and even then, the success is not secure), questions about the adequate time frame for international (adaptation) support have to be raised. Even if the USD100bnpledge (implying also large amounts of funding dedicated to adaptation) were advantageous in the presence and near future, this does not necessarily hold in the mid-term. As wealth and also the technological prospects (for adaptation) of individual developing countries improve, the beneficial allocative consequences of channeling international transfers towards them may deteriorate. Hence, a time-limit for or periodic reevaluation of the transfer-pledge from developed countries (Annex-I) seems advisable.

Finally, the lack of a stipulated conditionality of adaptation support in the Cancun Accords (i.e. adaptation support will not explicitly be subjected to marginal increases in developing regions' mitigation efforts) further enhances the 'adaptation transfer riddle', i.e. the question why industrialized countries are willing to pledge large amounts of funds for adaptation projects in developing countries. However, implicitly - as the specific requirements for international funds to be accounted for the USD100bn-pledge are not yet agreed upon - there might be some conditionality pending. If the developing countries would be defective in establishing a future global climate agreement and refuse to make own abatement commitments, industrialized countries might, e.g., define 'additionality' of climate funds in a rather broad way. As some recent calculations suggest (see e.g. Buchner et al. 2011) already current international climate finance almost achieves the USD100bn-mark, and thus, depending on the industrialized world's re-labeling efforts concerning these funds, the amount of new international financial flows dedicated to climate policy would vary.

As there is little justification from the allocation side for providing international adaptation assistance, the solution of the adaptation transfer riddle might therefore be mainly found in 
the 'distributional branch' (Musgrave 1959) of public policy, i.e., equity (see, e.g., Mendelsohn 2012 who makes a distinction between developed, developing and emerging countries) and fairness (see, e.g., Pittel and Rübbelke 2013) considerations may be important. Aspects concerning international law may also play a role (see, e.g., Tol and Verheyen 2004) as there might be the possibility that countries are held liable under international law if their emissions of greenhouse gases were to cause damage to other countries. Major emitters might seek to lower such a liability risk by offering adaptation assistance to strongly affected countries which in turn tends to reduce the climate change damage. ${ }^{21}$

\section{References}

Akai, N. (2003), "When do Cost Differentials among Privately Provided Public Goods make Income Transfer Policy Effective?," Economics Bulletin, 8, 1-7.

Althammer, W. and Buchholz, W. (1993), "Lindahl-Equilibria as the Outcome of a Noncooperative Game," European Journal of Political Economy, 9, 399-405.

Auerswald, H., Konrad, K.A. and Thum, M. (2011), Adaptation, Mitigation and Risk-Taking in Climate Policy, Working Paper No. 3320, CESifo (Munich).

Barrett, S. (2008), "Climate Treaties and the Imperative of Enforcement," Oxford Review of Economic Policy, 24, 239-258.

Bergstrom, T.C. (1989), Puzzles - Love and Spaghetti, The Opportunity Cost of Virtue, Journal of Economic Perspectives 3, 165-173.

Buchholz, W., Cornes, R.C. and Rübbelke, D. (2011), "Interior Matching Equilibria in a Public Good Economy: An Aggregative Game Approach," Journal of Public Economics, 95, 639-645.

Buchholz, W. and Konrad, K.A. (1994), "Global Environmental Problems and the Strategic Choice of Technology," Journal of Economics, 60, 299-321.

Buchholz, W. and Konrad, K.A. (1995), "Strategic Transfers and Private Provision of Public Goods," Journal of Public Economics, 57, 489-505.

Buchholz, W. and Peters, W. (2005), "A Rawlsian Approach to International Cooperation," Kyklos, 58, 25-44.

Buchner, B., Falconer, A., Hervé-Mignucci, M., Trabacchi, C. and Brinkman, M. (2011), The Landscape of Climate Finance, CPI Report, Climate Policy Initiative, Venice.

\footnotetext{
${ }^{21}$ There are currently strong international disputes about how to address 'loss and damage' associated with climate change impacts. At the COP in Doha in 2012, the first time the phrase 'loss and damage' had been explicitly addressed in an international legal document

(http://unfccc.int/files/meetings/doha_nov_2012/decisions/application/pdf/cmp8_lossanddamage.pdf).
} 
Buob, S. and Stephan, G. (2011a), On the Incentive Compatibility of Funding Adaptation, NCCR Research Paper 2011/02, University of Bern.

Buob, S. and Stephan, G. (2011b), "To Mitigate or to Adapt: How to Confront Global Climate Change," European Journal of Political Economy, 27, 1-16.

Cornes, R.C. (1992), Duality and Modern Economics, Cambridge University Press (Cambridge).

Cornes, R.C. and Hartley, R. (2007), “Aggregative Public Good Games,” Journal of Public Economic Theory, 9, 201-219.

Cornes, R.C. and Sandler, T. (1984), "Easy Riders, Joint Production and Public Goods," Economic Journal, 94, 580-598.

Cornes, R.C. and Sandler, T. (1994), "The Comparative Static Properties of the Impure Public Good Model,” Journal of Public Economics, 54, 403-421.

Cornes, R.C. and Sandler, T. (1996), The Theory of Externalities, Public Goods and Club Goods, Cambridge University Press (Cambridge).

Danziger, L. and Schnytzer, A. (1991), "Implementing the Lindahl Voluntary-Exchange Mechanism," European Journal of Political Economy, 7, 55-64.

Diamond, P.A. and McFadden, D.L. (1974), "Some Uses of the Expenditure Function in Public Finance," Journal of Public Economics, 3, 3-21.

Ebert, U. and Welsch, H. (2012), "Adaptation and Mitigation in Global Pollution Problems: Economic Impacts of Productivity, Sensitivity, and Adaptive Capacity," Environmental and Resource Economics, 52, 49-64.

Ekins, P. (1996), "How Large a Carbon Tax is Justified by the Secondary Benefits of $\mathrm{CO}_{2}$ Abatement?," Resource and Energy Economics, 18, 161-187.

Gorman, W.M. (1980), "A Possible Procedure for Analysing Quality Differentials in the Egg Market," Review of Economic Studies, 47, 843-856.

Guttman, J. M. (1978), “Understanding Collective Action: Matching Behavior," American Economic Review, 68, 251-255.

Guttman, J. M. (1987), “A Non-Cournot Model of Voluntary Collective Action,” Economica, 54: $1-19$.

Heuson, C., Peters, W., Schwarze, R. and Topp, A.-K. (2012), Which Mode of Funding Developing Countries' Climate Policies under the Post-Kyoto Framework?, Discussion Paper 10/2012, UFZ (Leipzig).

Ihori, T. (1996), "International Public Goods and Contribution Productivity Differentials," Journal of Public Economics, 61, 139-154.

Ingham, A., Ma, J. and Ulph, A. (2005a), Can Adaptation and Mitigation Be Complements?, Working Paper 79, Tyndall Centre for Climate Change Research (Norwich).

Ingham, A., Ma, J. and Ulph, A. (2005b), How Do the Costs of Adaptation Affect Optimal Mitigation When There is Uncertainty, Irreversibility and Learning?, Working Paper 74, Tyndall Centre for Climate Change Research (Norwich).

Ingham, A., Ma, J. and Ulph, A. (2007), "Climate Change, Mitigation and Adaptation with Uncertainty and Learning,” Energy Policy, 35, 5354-5369. 
Kane, S. and Shogren, J.F. (2000), "Linking Adaptation and Mitigation in Climate Change Policy," Climatic Change, 45, 75-102.

Lancaster, K.J. (1966), “A New Approach to Consumer Theory," Journal of Political Economy, 74, 132-157.

Mendelsohn, R. (2012), "The Economics of Adaptation to Climate Change in Developing Countries," Climate Change Economics, 3, 21 pages.

Musgrave, R.A. (1959), The Theory of Public Finance, McGraw Hill (New York).

Neary, J.P. and Roberts, K.W.S. (1980), "The Theory of Household Behaviour under Rationing," European Economic Review, 13, 25-42.

Ono, T. (1998), "Consumption Externalities and the Effects of International Income Transfers on the Global Environment," Journal of Economics, 68, 255-269.

Paavola, J. and Adger, W.N. (2006), "Fair Adaptation to Climate Change," Ecological Economics, 56, 594-609.

Pittel, K. and Rübbelke, D.T.G. (2013), "International Climate Finance and Its Influence on Fairness and Policy," The World Economy, forthcoming.

Rothbarth, E. (1940-41), "The Measurement of Changes in Real Income under Conditions of Rationing," Review of Economic Studies, 8, 100-107.

Rübbelke, D.T.G. (2002), International Climate Policy to Combat Global Warming: An Analysis of the Ancillary Benefits of Reducing Carbon Emissions, Edward Elgar, Cheltenham.

Tol, R.S.J. (2005), "Adaptation and Mitigation: Trade-offs in Substance and Methods," Environmental Science and Policy, 8, 572-578.

Tol, R.S.J. and Verheyen, R. (2004), "State Responsibility and Compensation for Climate Change Damages - a Legal and Economic Assessment," Energy Policy, 32, 1109-1130.

UNFCCC (2011), Report of the Conference of the Parties on its sixteenth session; Addendum: Part Two: Action taken by the Conference of the Parties at its sixteenth session, $\mathrm{FCCC} / \mathrm{CP} / 2010 / 7 /$ Add.1.

Zehaie, F. (2009), "The Timing and Strategic Role of Self-Protection," Environmental and Resource Economics, 44, 337-350. 